SHS Web of Conferences 7, 02003 (2014)

DOI: $10.1051 /$ shsconf / 20140702003

(C) Owned by the authors, published by EDP Sciences, 2014

\title{
Study on Domestic and Foreign Policy in Nanotechnology R\&D
}

\author{
Zhang Yujuan, Zhang Wei
}

Beijing Science and Technology Information Research Institute, 100044 Beijing, China

\begin{abstract}
Nanotechnology as one of the technology sector has penetrated into every field, and to become the dominant technology in the new industrial revolution. The article analyzes the policy of nanotechnology research and technology, and the effect of policy implementation in United States, Japan, several EU countries, and proposes the policy references of nanotechnology R\&D.
\end{abstract}

Keywords. nano; nanotechnology; R\&D; national science and technology policy; proposal

\section{Introduction}

Nanotechnology has become one of the most active areas of the power of technology. Especially the last decade, it maintained a rapid development, permeated and integrated the various research areas, and has an impact on the economy and society. These caused governments to attach highly attention, to introduce policies to support the development of nanotechnology. In view of the above situation, the article proposed the study, which found policy recommendations that will improvement nanoscience and nanotechnology policy.

\section{Basic situation of policy}

\subsection{Basic situation of policy abroad}

As the leader of nanotechnology research, development and application, the United States Government included nanotechnology in the key technology areas for priority development into the national strategic planning. Especially the past ten years, the United States Government has invested over $\$ 16$ billion in nanotechnology $y^{[1]}$. At the same time it drafted and carried out a range of policies to support the development of nanotechnology ${ }^{[2]}$. Representative policies were "Nano-technology Strategy" in 1999, "The Project of NNI" in 2000, "The $21^{\text {st }}$ Century Nanotechnology Research and Development Act" in 2003, "The Strategy for American Innovation" in 2011, and NSI released a number of plans in the past years. These policies strengthened legislative work, standardized budget management, strengthened evaluation work, and so on. They laid the foundation for the United States of nanotechnology development ${ }^{[1,3]}$.

The Japan Government implemented some policies about the nanotechnology the early 1980s. As a key technology areas of national development strategies the nanotechnology and materials and life sciences have been incorporated into the second "Science and Technology Basic Plan" in 2001 ${ }^{[4]}$. 
"The Nanotechnology Support Project" beginning 2002 linked researches scattered across many professional researchers ${ }^{[5,6]}$. The third "Science and Technology Basic Plan" in 2006 continued nanotechnology as one of "Four Key Areas to Promote", and developed the appropriate strategies to promote the nanotechnology ${ }^{[7]}$. These policies reflected the highest decision-making, the system of top-level design and overall coordination, showed the characteristics of a high investment and university-industry cooperation.

EU has given unprecedented attention on nanotechnology at the beginning of this century. The nanotechnology field as a top priority in "The Sixth Framework Program" has got the support of $€ 1.3$ billion. More attention to research and development have focused to nanotechnology in "The Seventh Framework Program", and about $€ 35$ billion budget for the R\&D of nanotechnology and nanoscience and material and new manufacturing technology, an increase of $169 \%$. At the same time EU countries developed their nanotechnology R\&D program to enhance their international status of nanoscience and nanotechnology ${ }^{[8]}$.

Since 1997, budge about $\$ 50$ million has been for nanotechnology in the German Ministry of Education and Research. German proposed "Pre-competitive" programs of nanotechnology research and development in 1998. German Federal Government published "White Paper on Innovation Funding", announced fund research to focus on new technology including nanotechnology in $2000^{[2,4]}$. "Strategic Framework Action Plan for Nanotechnology", "Industrial and Social Innovation Program Materials", "A Major Research and Development Programs" in 2002-2004 focused on identified strategic position in nanotechnology innovation in development of German. The German Government approved "The Nanotechnology Action Plan 2015" in 2011, which was the first time for government actions to regard nanotechnology in the high-tech strategic framework ${ }^{[9]}$. The plan included six areas, one was about the research and transfer in the climate, health and other key area, one was about the research of human and environment danger, etc. In recent years German continued to adopt targeted policies to increase funding for nanotechnology research funding ${ }^{[10]}$.

The France implemented "The Micro Science and Technology Plan" to fund \$ 120 million to mainly engaged in the research of MEMS and micro-systems ${ }^{[4]}$. Afterward the government launched "The Competitiveness Center Program" and "Center of Excellence" to engage in nanotechnology research, and gained about $€ 1.5$ billion to support the development ${ }^{[11]}$. The France Government focused on the development of medical electronics and nanotechnology, and continued across Europe the most favorable local tax policy in 2009-2011 ${ }^{[12]}$.

UK nanotechnology research level has been largest in the world, these thank to government funding for nanotechnology development started early, and attaching great importance. The earliest policy was "The Five-year Plan (1994-1999)", it invested about \$ 1 million to nano-particles research $^{[4]}$. "White Paper About 21st Century Science and Technology Innovation Policy" was published in 2001, and announced a total investment $£ 44$ million to support nanotechnology basis research. The main behavior of nanotechnology policy was "The New Manufacturing Space - UK Nanotechnology Strategy" ${ }^{,[13,14]}$. The British Standards Companies launched a series of standards to guide the development of nano-science ${ }^{[15]}$. In recent years, UK Government invested heavily funds in the nanotechnology research centers established in the cross-renowned universities, encouraged to conduct researchers to improve basis research. All nanotechnology would be divided into three generations and nine degrees, they will be support according to the generation and grade. Once the technology is mature, it will be transferred into the market, developed and applied. Currently the UK Government has played nanotechnology applications in the environment, population and IT areas as a priority and funded ${ }^{[16]}$.

\subsection{Basic situation of policy domestic}

The China Government supported projects of nanotechnology research in the 1980s, after some departments continued to support the research projects, such as the National Natural Science Foundation of China, Ministry of Science and Technology of the People's, Ministry of Education of the People's Republic of China, Chinese Academy of Sciences, and so on. 
Since 1990, "Climbing Program" of State Scientific and Technological Commission began funded nano-science. "973" set up nano-materials and nano-structures research as project alone in 1999. And the same time "863" started to support nano-research in 1990. The National Natural Science Foundation of China commenced to fund nanotechnology research in $1991^{[17]}$.

The first official nanotechnology policy was "National Nanotechnology Program for the Development of Science and Technology (2001-2010)", issued by the Ministry of Science, etc. It marks nanotechnology system construction framework program form in China.

Under the guidance of "Nano-Plan", the Ministry of Science has started to involve nano-devices, nano-bio and nano-materials research projects. The National Natural Science Foundation of China was not only to strengthen support for nano-science-related research in various disciplines, and launched "A Major Research Program of Basic Research in Nanotechnology", Chinese Academy of Sciences has launched nano-materials, etc. programs. "Long-term Science and Technology Development Plan (2006-2020)" established in 2006 set up nano-research as major project, and arranged it as the basic science research of the four main one aspect during this period. "Eleventh Five-Year of International Science and Technology Cooperation Program for the Implementation" issued by the Ministry of Science proposed nanotechnology as key areas for international cooperation. The Ministry of Science formulated and implemented "Twelve Five Special Planning for Nanotechnology research National Research Program" and so on in 2011. These polices created a conductive policy environment for the nanotechnology development, mobilized and inspired the creativity of science and technology workers, and effectively improve the interaction of nanoinnovation chain and industry.

\section{Achievement and insufficient of policy}

\subsection{Achievement and insufficient of policy abroad}

The nanotechnology sparked increasing competition among governments in the world, especially in developed countries, enhanced the overall level of $R \& D$ in nanotechnology. These countries' achievements of nanotechnology papers, patents rank in the world by the government's strong support, and accumulated a wealth of experience in nanotechnology research program, management mechanism, research platform and so on.

According to rough statistics, the U.S. Congress has allocated about $\$ 16.5$ billion for nanotechnology R\&D budget in 2001-2012 ${ }^{[18]}$. Simultaneously nanotechnology policy remained steady implementation. It encouraged research staff to cooperate with other researcher in the world, play the role of coordination. The polices focused on $\mathrm{R} \& \mathrm{D}$ on the one hand have laid a good foundation for the industrial development of the U. S. of nanotechnology, the other hand played an important role in the process of national innovative, economic recovery. Given the dual nature of things, in the development process of nanotechnology strategy policy the United States also takes into account the risks of nanotechnology and its ethical and social problems. It is worth noting it showed some sufficient in the implementation process. Such as "The National Nanotechnology Initiative" lacked of overall deployment strategy planning project management mechanism was not perfect, assessment criterion has not been considered and so on. To solve these problems, from academics to the federal government are actively make recommendations for policy makers.

The second and third "Science and Technology Basic Plan" get a lot of world pride achievements, such as successfully prepared carbon nano-tubes, photo-catalyst, and so on ${ }^{[19]}$. Though compared with other countries, Japan nanotechnology although is very strong, but maintains this status, it maybe loses the advantage in the future. Based on this situation, Japan begins to strengthen R\&D of nanotechnology and materials support, and reinforce personnel training, etc.

"The Seventh Framework Program" in EU paid more attention to the training of young scientists, focused attention on the combination of basic science and applied research, eliminated bureaucracy in research management, support small and medium enterprises to participate in research programs. After nearly five years of efforts, European Research and Development Team received a major 
innovative technological breakthrough in the super surface coatings research, and created a new category of substances materials ${ }^{[20]}$. Meanwhile, European Nano-bond Research Team has successfully developed fabrics against "Super-bugs". Clinical trials showed it killed approximately $99.99 \%$ of bacteria, even if after textiles dipped 70 times it was still more than $90 \%$ can be achieved. The technology has been applied for several patents. At present, the team is going product development application of technology, for example medical linen coat, medical mattresses, bandages, medical products and so on.

\subsection{Achievement and insufficient of policy domestic}

With our government and academics attention and support for nanotechnology, it gained a series of achievements and development. Especially during "the Eleventh Five-Year", nanotechnology papers, and patent applications cited frequency authorization has been ranked in the world. Developed a series of national and international standards has been development and implement. These measures have laid a good foundation for the industrial applications of nanotechnology.

Although research and development of nanotechnology funding showed an increasing trend in China, but compared with the U.S., Japan, EU and other technology country, the gap is still large. Because nanotechnology equipment prices are expensive, the majority of R\&D institutions simply cannot afford. To depth in nanotechnology research, the country needs to increase investment.

Because the original innovation was insufficient and technology was lower, it needs to strengthen policy efforts to intensify original innovation incentives and so on.

\section{Foreign policy implications and measures and suggestions}

Nanotechnology research has been carried out in China earlier, there has formed a certain influence in the world, has its own characteristics, the research team. Combined with our lack of policies of nanotechnology research and development and the experience of foreign countries in nanotechnology research and development of stronger, we get the following revelation. It should be put the nanotechnology into priority development areas, give high priority in the overall deployment of the National Science and Technology Development Strategy. It should accelerate the pace to innovative the policy, form a sound policy system in nanotechnology research and development, industrial development. It should continue to increase R\&D investment, attract social capital into the ranks of nanotechnology research and development, encourage research and development of corporate finance in the capital markets, especially strengthen policy support, such as finance, taxation, finance, etc. It should create a good social environment, and actively participate in international nanotechnology standards, in order to occupy the driving position in international competition. It should innovative education model for nanotechnology researcher, implement flexible policies to provide protection for the intellectual development of nanotechnology. It should actively explore and optimize mode of transformation of research achievement, draft corresponding policies nanometer technology to pave the way to market.

It should strengthen exchanges and cooperation, construct information smooth exchange platform, actively participated in international nanotechnology standards, access to the driving position in international competition.

\section{Acknowledgment}

This work was financially supported by Beijing Municipal Science and Technology Commission. 


\section{References}

1. J. J. Zhao, Development and Strategic Deployment of Nanotechnology in United States[J]. Global Science, Technology and Economy Outlook, 2011(26):38-45.

2. H. L. Zhao, S. Wang. The Preliminary Analysis of the Properties and Enlightenment of Nanotechnology Policy in America, Germany and Japan[J]. Scientific Management Research, 2007(25).

3. 2012 World Technology Development Review: Technology Policy. [EB/OL]. [2013-01-08], http://www.bioon.com/trends/news/539622.shtml

4. Ministry of Science and Technology of the People's, Nanotechnology Development Research report compilation (2002), 2002.

5. Hideki Shirakawa, Japan Science and Technology Policy and Nanotechnology," [EB/OL]. [200404-15].

http://www.tsinghua.edu.cn/publish/news/4211/2011/20110225231430593118582/201102252314 30593118582_html

6. Ministry of Science and Technology of the People's, the Latest Development Trend of International Nanotechnology-international Science and Technology Development Report[M], Science Press, 2006:79-81.

7. S. Wu. Development Strategy and Important Japan Government for Nanotechnology[J]. Global Science, Technology and Economy Outlook, 2008(23):16-21.

8. World Development Trend and Characteristics of Nanotechnology, [EB/OL]. http://www.doc88.com/p-017651016932.html

9. 2011 World Technology Development Review: Technology Policy. [EB/OL]. [2012-01-04], http://www.edu.cn/zi_xun_1170/20120104/t20120104_726699_3.shtml

10. Germany Nanotechnology Action Plan 2015. [EB/OL]. [2011-01-17], http://www.cas.cn/xw/kjsm/gjdt/201101/t20110117_3063081.shtml

11. Q. F. Xia, Y. M. Sun, Overview of Nanotechnology R\&D and Industrialization in France[J]. Global Science, Technology and Economy Outlook, 2008(23):5-9.

12. Implement Policies of R\&D Expenses Tax in France Boost the Development of Electronic and Medical Nanotechnology [EB/OL]. [2011-08-26], http://www.hqew.com/tech/news/323996.html

13. R. H. Feng, J. Zhang, Q. Liu. The Research Plan and Progress of the Main National Nanotechnology Strategic [J]. Science and Technology Progress and Policy,

14. Department of Trade and Industry. New Dimensions for Manufacturing: A UK Strategy for Nanotechnology[R]. London: Department of Trade and Industry, 2002:1- 74.

15. BSI British Standards Launched Nanotechnology, http://www.docin.com/p-11095543.html

16. Z. Cui. The Status and Strategic Planning of Nanotechnology in England http://www.sinano.cas.cn/xwdt/xwdt/200903/t20090320_2278253.html

17. L. X. Ou, Z. Q. Hu. The Formation, Evolution Process of Nanotechnology Innovation System in China and Suggestions on Countermeasures[J]. Bulletin of the Chinese Academy of Sciences, 2010(25):465-471.

18. X. F. Qi. The Analysis on National Nanotechnology Initiative Strategic Planning and Development in U.S. [J]. Dual Use Technologies and Products, 2012(8):15-17.

19. X. L. Zhu, The Situation and Countermeasures of Nanotechnology and Material in Japan[J]. Advanced Material Industry, 2009(9):51-54.

20. The Super major breakthrough of surface coating technology in EU," [EB/OL]. [2013-07-12], http://www.most.gov.cn/gnwkjdt/201307/t20130712_107164.htm 